Original Research Paper

\title{
Identification of Children Learning Styles Using Elicitation Application
}

\author{
${ }^{1,2}$ Mira Kania Sabariah, ${ }^{1}$ Paulus Insap Santosa and ${ }^{1}$ Ridi Ferdiana \\ ${ }^{I}$ Department of Electrical and Information Engineering, Universitas Gadjah Mada, Yogyakarta, Indonesia \\ ${ }^{2}$ School of Computing, Telkom University, Bandung, Indonesia
}

\author{
Article history \\ Received: 11-05-2020 \\ Revised: 13-06-2020 \\ Accepted: 01-07-2020 \\ Corresponding Author: \\ Mira Kania Sabariah \\ Department of Electrical and \\ Information Engineering, \\ Universitas Gadjah Mada, \\ Yogyakarta, Indonesia \\ Email: mirakania@telkomuniversity.ac.id
}

\begin{abstract}
Learning styles is one aspect of pedagogy that needs to be considered in the learning process. Understanding of material will be achieved if it is by the learning styles. Children do not have experience in the learning process, so identification of children learning styles is needed. The cognitive, psycho-motor and emotional abilities of children in each varying age range become a factor that determines learning styles. Learning styles tend to be recommended to children in the form of visual, audio, $\mathrm{read} / \mathrm{write}$ and kinesthetic. Identification can be made towards learning styles that are by the child's preferences. The use of digital applications will be more accurate when compared to questionnaires in identifying learning styles. The presentation of interactive material and immersive in each learning styles can help identify children's learning styles. The assessment of material understanding was clarified in elicitation apps. The material evaluation was presented in the form of a set of questions related to the material presented. Interactions in the evaluation activities in the apps were presented according to the child's learning styles. Output produced by the application can be used by learning application developers, teachers, or parents in identifying children's learning styles.
\end{abstract}

Keywords: Learning Styles, Children, Learning Process, Children's Learning Styles

\section{Introduction}

Learning activities are said to be successful if students understand the learning material was delivered (Kazu, 2009). The pedagogical aspect that is a concern to make that understanding of this material was achieved is through the application of appropriate learning styles (Cano et al., 2016). Learning styles that were recommended for children are visual, audio, read/write and kinesthetic (Cano et al., 2016). The four learning styles were chosen because the child was considered having no learning experience. That is different from adults who have had learning experiences. Children in their development have four types of developmental age levels (Santrock, 2012). Each level has an age range that affects cognitive, psychomotor and emotional abilities. These factors affect the learning styles that suits each child. The success of understanding a material can be measured when students successfully solved a case or question.

The use of digital media in the learning process of children is currently widely used (Kanala et al., 2013), (Skiada et al., 2014). The reason is that digital media was considered to be more interactive in delivering learning material (Budiman et al., 2020). Besides, digital media was considered to be able to present various types of learning styles (Angelia et al., 2015). This phenomenon is certainly the basis for the need to know children's learning styles so that the use of digital media becomes powerful and accurate (Graf et al., 2008). Identification of learning styles can also be made in defining the requirements of a child's learning application (Cano et al., 2016). The use of the Visual, Auditory, Reading/writing and Kinesthetic (VARK) questionnaire is now often used to identify learning styles (Alzain et al., 2018). However, the results will be accurate if using digital media (Graf et al., 2008). Presentation of material and evaluation of content using digital media was considered to be efficient in verifying and validating learning styles (Tang et al., 2013). Based on that, the research question is how to make elicitation applications that can identify children's learning styles. The objective of this research was to make a tool that can give data and information about the child's learning styles. The application was expected can effective in given data to identify children's learning styles. 


\section{Elicitation Application for Children Learning Applications}

User requirements are important to achieved user satisfaction (Wiegers and Beatty, 2013). User desires on the application were expressed in user requirements. The way to get user requirements is to do the requirements elicitation process (Robins et al., 2007). The failure of the elicitation requirements process often occurs, one of which is the mismatch of aspects that were dug with the content to be resolved (Gonzales and Leroy, 2011; Moser et al., 2014; Anwar and Razali, 2016). In developing child learning applications, requirements from pedagogical aspects need to be well presented. One aspect of pedagogy that needs to be explored is the child's learning styles. The reason is that children do not have experience in the learning process. Each child can have a different learning style (Kanala et al., 2013). It is not easy to get a learning style that suits the child's preferences. The use of digital applications is one way that can be used to obtain these requirements (Mazzone, 2007; Gonzales and Leroy, 2011).

Elicitation applications for children's learning applications were made to assist the elicitation. The team using apps when gathering a set of requirements. In this application, there is functional to explore aspects of pedagogy, especially learning styles. This application applies the Visual, Auditory, Reading/writing and Kinesthetic (VARK) learning styles. The reason VARK was used is suitable for children who do not have learning experience (Cano et al., 2016). Figure 1 is a flowchart of the application of the VARK learning styles in elicitation applications (Sabariah et al., 2020). In the elicitation application, one of the material contents was presented in all four types of learning styles. Children as participants will be given a choice of learning styles that are following their preferences for a material.

Before choosing a learning styles in the application, identification was made using the VARK questionnaire. The VARK questionnaire was used because it could be used to determine learning styles (Alzain et al., 2018). The VARK questionnaire was given with language modification and questions that were appropriate for the child's persona. The elicitation team accompanied the technical filling out of the questionnaire by children. The elicitation team reads the questionnaire and if anything is unclear, the team will help explain it to each child respondent.

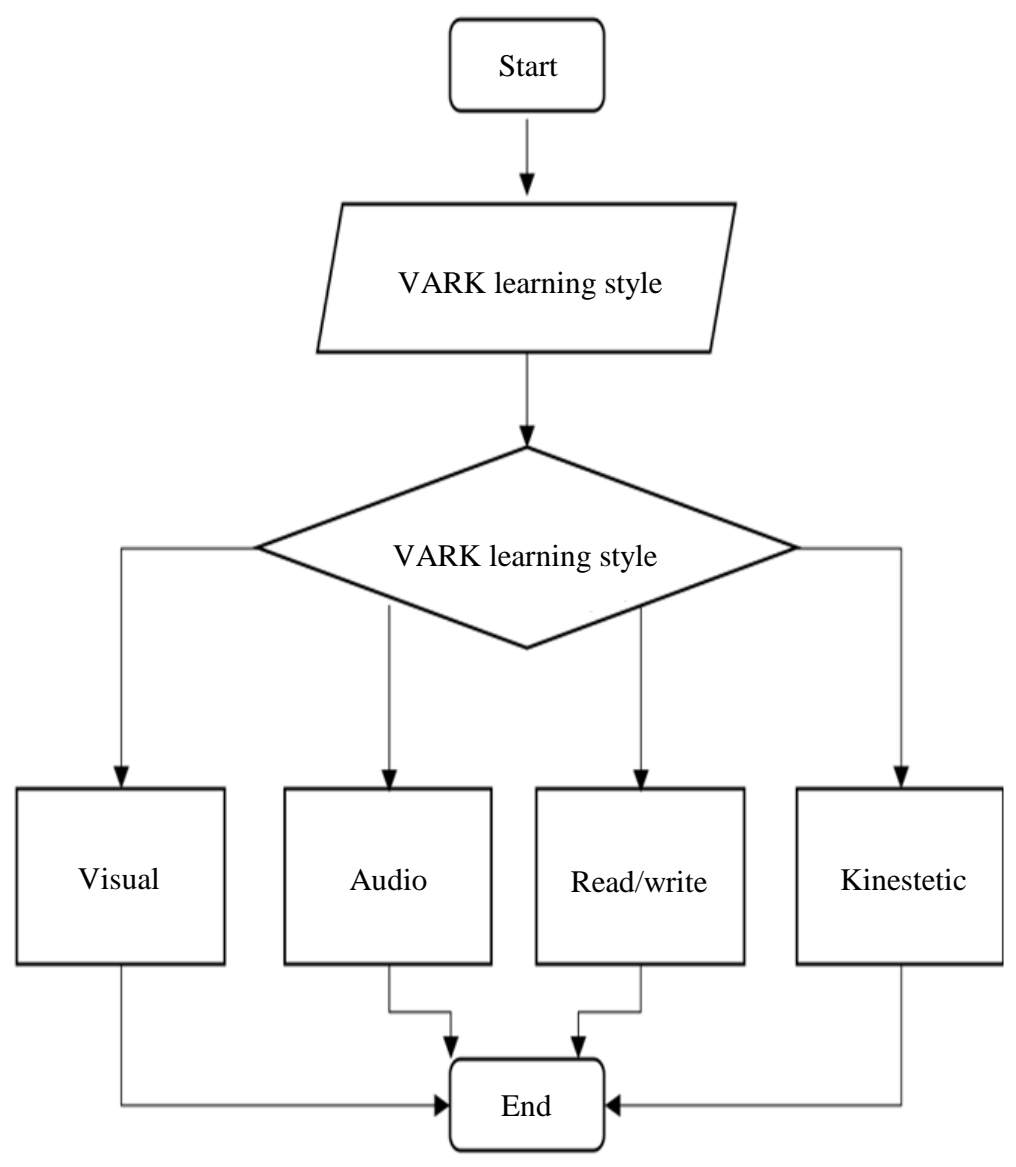

Fig. 1: Flowchart of applying the VARK learning styles (Sabariah et al., 2020) 
Elicitation application will record the value of children's satisfaction with the learning styles that they have chosen. Assessment of learning styles is done by participants through satisfaction value using smiley faces (emoticons) (Mazzone and Iivari, 2010). Figure 2 shows a display of the material assessment satisfaction activities that have been presented. The application was made in Indonesian because the target users are children in Indonesia and based on mobile technology. Components of the application interface were tailored to target children aged 6-8 years. Measurement of user satisfaction from this application has been carried out and the resulting value $>=80 \%$, which means that the user understands all application components (Sabariah et al., 2020). Apps on mobile technology had effective for children (Politi and Demokritos, 2020). When the child has done a satisfaction assessment, the app will display an evaluation of the material. There is a set of questions given and presented according to the material that was delivered.

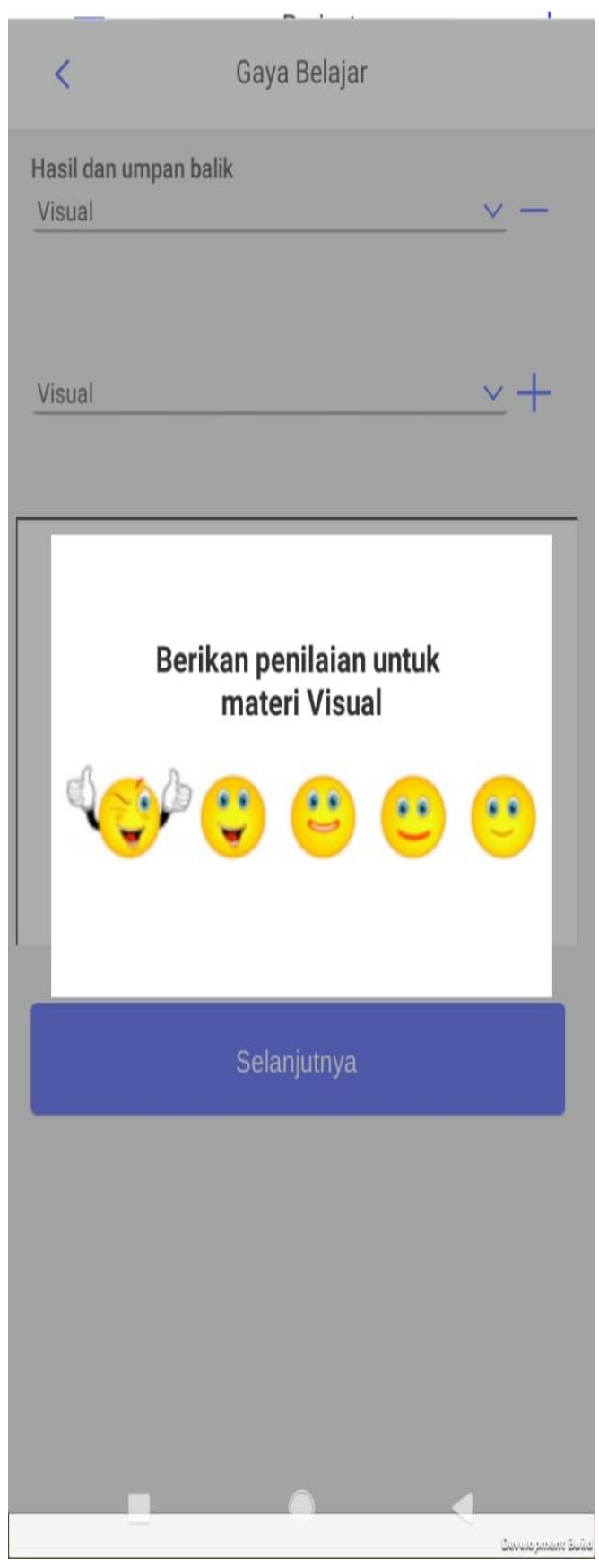

Fig. 2: The interface of assessment satisfaction 
Questions given in the application were adjusted to the material provided. Material resources and questions obtained through textbooks for elementary school children aged 6-8 years. So, validation for the questions given is not done. Another reason is that the primary purpose of this application made is to provide data requirements when the identification of learning styles. The data will be more structured and accurate if obtained directly from the target, namely children. The output of the application presents data in a structured manner, which was expected to help the next process efficiently and accurately. Material content and questions can be updated as needed. The answers to each question were stored in the application database for further analysis needs.

\section{Research Methodology}

The research was using a case study method with the content corresponding as a target participant's knowledge. The participants being children aged 6-8 years. The target age was chosen because of that age suitable for using technology. When conducting the case study, the child will be identified early in his learning styles through a VARK questionnaire that has been modified by language and question form. Then the results of the survey become the basis for choosing the learning styles that exist in the elicitation application. When the child finishing sees the material in the application according to the learning styles, the child then assessing the satisfaction of the content.

The satisfaction has means, the children perceive the material presented and the content meets the element of usability (MacFarlane et al., 2005). The assessment uses a scale value of 1-5 using smiles face (Mazzone and Iivari 2010). Finish viewing the material, the child will be asked to answer a set of questions to assess the material presented. All children's activities will be recorded in a database in the elicitation application for further processing. Figure 3 is a flowchart of stages in the research conducted.

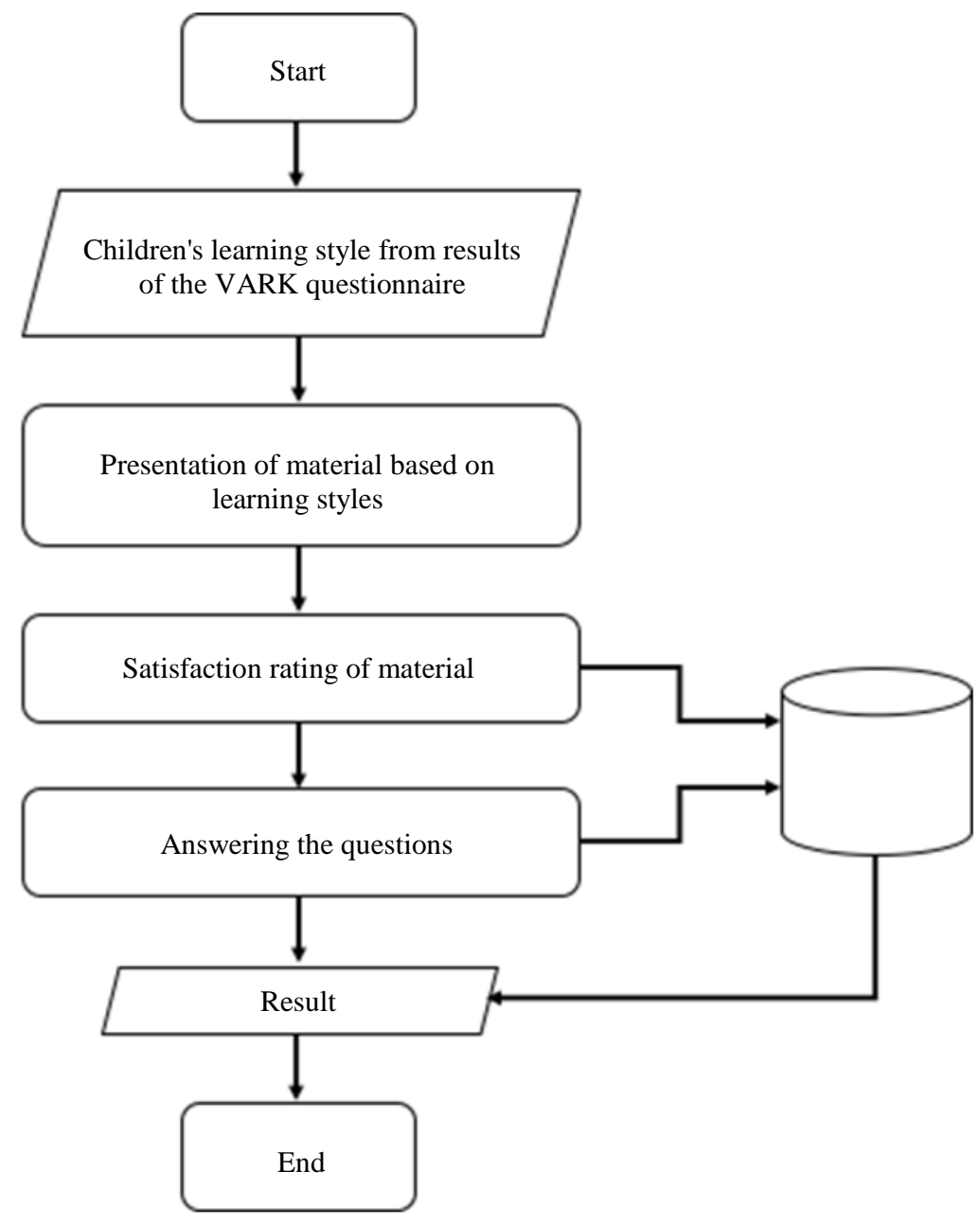

Fig. 3: Flowchart of research methodology 


\section{Results}

\section{Case Study}

Case studies applied to elicitation applications are material about the introduction of fruits and vegetables. The reason was chosen is that at 6-8 years have cognitive abilities are recognizing and remembering an object that exists in real life. The material presented types of vegetables and fruits. The evaluation questions are also related to the content. Questions were presented according to the level of children's thinking skills related to that content (Sabariah et al., 2020).

\section{Participants}

Participants were Indonesian children aged 6-8 years as many as 37 child respondents with a gender distribution consisting of 14 boys and 23 girls. Children's academic abilities tend to be intermediate and their learning styles unknown. Table 1 describes the demographics of the participants involved.

\section{Results}

Learning styles data collection was done in two stages. The first stage uses the VARK questionnaire and the second stage uses elicitation applications. The output from the first stage is the input on elicitation applications. The learning styles in the first step was used to choose the form of presentation of the material on apps. The results of data retrieval using elicitation applications were divided into two types. The first type of data is the data value of the child's satisfaction with the material presented in the application. While the second type of data is data on children's results in answering a set of questions in the evaluation section. Table 2 is an example of the data results from the elicitation apps. In the application database, learning styles, the value of content presentation satisfaction, the number of right and wrong answers are recorded.
The two types of data had obtained and the next step is data analysis. Satisfaction value (S) of each answer criterion value (E) can be used as a reference in deciding the learning styles that suits the child's preferences. The value of the answer criteria was divided into three, True $(\mathrm{T})$, False $(\mathrm{F})$ and True-False $(\mathrm{T}=\mathrm{F})$. $\mathrm{T}$ criteria are for answers with more correct values. F criteria are for the number of incorrect answers more. $\mathrm{T}=\mathrm{F}$ criteria are the answer to the number of true and false values that are the same. Based on these criteria, the results obtained from 37 child respondents with the composition as in Table 2 . About 12 children rated the satisfaction of presenting the material with a value of 5 (delighted) and had the correct answers to the questions given. Seven children rated the presentation of material with a value of 5 but had more wrong answers than the questions given. Ten children assess the presentation of material with a value of 5 but have the same number of right and wrong answers. In Table 3 could be concluded that a count of 14 or $38 \%$ of child respondents have learning styles that match their preferences. The value was the accumulation of the results of the correct answer to the value of satisfaction 5 (very satisfied) and 4 (satisfied). Figure 4 is a data chart of the analysis of learning styles. The assessment of material satisfaction directly by the child indirectly represents the child's learning styles.

Children's interactions and behavior can also be observed with the use of digital media. Meanwhile, if identification was carried out using a questionnaire, it will not be accurate because it was presented in a nondigital form. In addition to assessing material satisfaction, an assessment of material understanding was also carried out. The evaluation of material understanding is a way to measure whether the material presented has been under-stood (Runeson et al. 2012; Tran and Anvari, 2016).

The assessment results are a measure of the success of a learning styles declared successful or not. Criteria for evaluating material understanding can be based on each environment.

Table 1: Demographics of participants

\begin{tabular}{|c|c|}
\hline Cognitive skills & Technological experience \\
\hline 1. Get to know the primary colours. & 1. Accustomed to using a smartphone. \\
\hline 2. Get to know necessary objects such as animals, plants. & 2. Have experience use of search engine applications (Google), \\
\hline 3. Recognize Latin letters and numbers. & video applications (YouTube), other learning applications \\
\hline 4. Can read. & and game applications for learning and entertainment. \\
\hline 5. Can Write. & 3. Accustomed to playing games on a smartphone. \\
\hline 6. Can calculate according to the as & \\
\hline
\end{tabular}

Table 2: Example of the data results from the elicitation apps

\begin{tabular}{lllll}
\hline Participants & Learning styles (VARK questionnaire) & Value of S & Value of T answer & Value of F answer \\
\hline P1 & Kinesthetic & 5 & 10 & 2 \\
P2 & Visual & 5 & 4 & 8 \\
P3 & Visual & 5 & 6 & 6 \\
\hline
\end{tabular}




\begin{tabular}{llllr}
\hline & S & & \\
E & ----1 & 3 & 4 \\
\hline T & 1 & 2 & 1 & 2 \\
F & 0 & 0 & 1 & 1 \\
T F & 0 & 0 & 2 & 1 \\
\hline
\end{tabular}

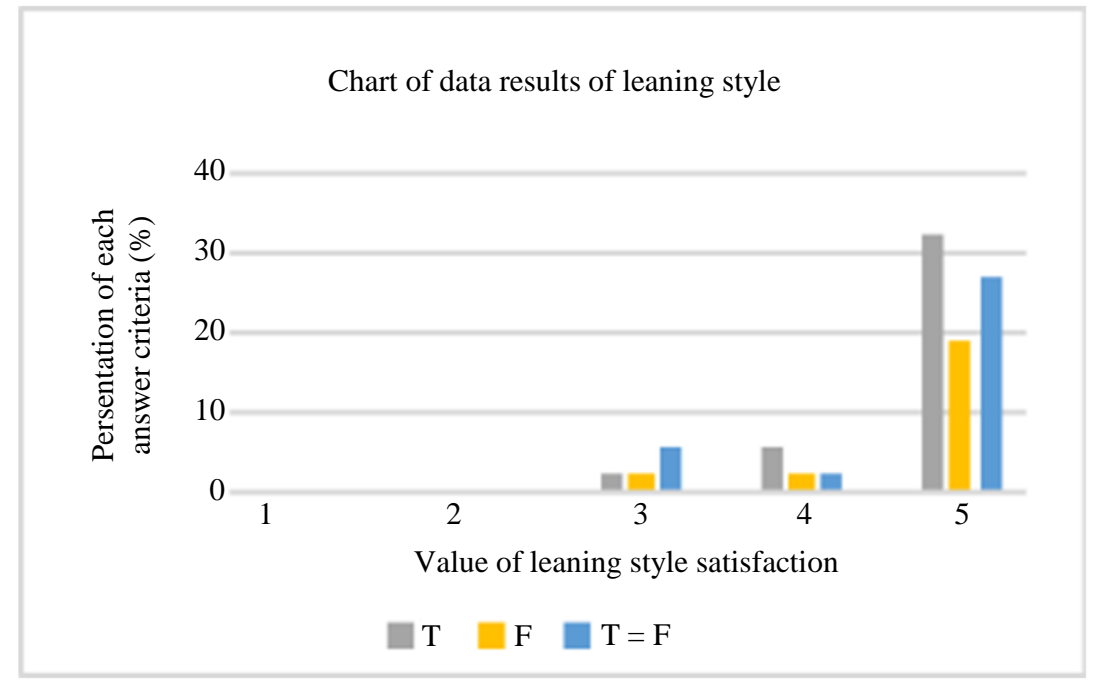

Fig. 4: Chart of data results of analysis learning styles

\section{Conclusion}

The conclusion from this study that the elicitation application made can help in identifying children's learning styles. The results of the elicitation application in the form of material satisfaction scores and the results of the material evaluation can be one indicator in determining children's learning styles. This activity can help application developers and even teachers or parents find out about children's learning styles. If the results were given are not appropriate, then it can be identified again with this elicitation application. Practically elicitation applications can also facilitate developers in defining the learning styles requirements of the learning application to be built. The use of digital technology that can hold data in the form of a database helps accelerate the process of learning styles analysis. Future work is to enrich the presentation of material that is suitable for all types of the age range of child development. The questions are also presented based on the level of thinking skills of children.

\section{Acknowledgement}

This research was supported by The Indonesia Endowment Fund for Education (Lembaga Pengelola Dana Pendidikan/LPDP) and Telkom University.

\section{Funding Information}

This research was supported by The Indonesia Endowment Fund for Education (Lembaga Pengelola Dana Pendidikan/LPDP) and Telkom University.

\section{Author's Contributions}

Mira Kania Sabariah: Contributed to conduct the experiment and prepare the draft of this paper.

Paulus Insap Santosa and Ridi Ferdiana: Revised this paper.

\section{Ethics}

Ethical committee approval from Medical and Health Research Ethics Committee, Faculty of Medicine, Public Health and Nursing Universitas Gadjah Mada - Dr. Sardjito General Hospital. This publication got the consent of all participants, their parents and their teachers.

\section{References}

Alzain, A., S. Clark, A. Jwaid and G. Ireson, 2018. Adaptive education based on learning styles: Are learning style instruments precise enough? Int. J. Emer. Technol. Learn. 13: 41-52.

DOI: 10.3991/ijet.v13i09.8554 
Angelia, S., N. Ohta and K. Sugiura, 2015. Design and evaluation of educational kinesthetic game to encourage collaboration for kindergarten children. Proceedings of the International Conference on Advances in Computer Entertainment Technolog, (CET' 15), ACM, pp: 1-5.

DOI: $10.1145 / 2832932.2832967$

Anwar, F. and R. Razali, 2016. Stakeholders selection model for software requirements elicitation. Am. J. Applied Sci. 13: 726-738.

DOI: 10.3844/ajassp.2016.726.738

Budiman, E., U. Mulawarman and A. Rosales-Pérez, 2020. A labyrinth game for blind children using problem solving learning model. Int. J. Emer. Technol. Learn., 15: 58-71. DOI: $10.3991 /$ ijet.v15i02.11375

Cano, S., C. Collazos, H.M. Fardoun and D.M. Alghazzawi, 2016. Model based on learning needs of children. Proceedings of the International Conference on Social Computing and Social Media, (CSM' 16), Springer, pp: 324-34. DOI: 10.1007/978-3-319-39910-2_30

Gonzales, C.K. and G. Leroy, 2011. Eliciting user requirements using appreciative inquiry. Empirical Software Eng., 16: 733-772. DOI: $10.1007 / \mathrm{s} 10664-011-9156-\mathrm{X}$

Graf, S., Kinshuk and T.C. Liu, 2008. Identifying learning styles in learning management systems by using indications from students behaviour. Proceedings of the 8th International Conference on Advanced Learning Technologies, Jul. 1-5, IEEE Xplore Press, Santander, Cantabria, Spain, pp: 482-486. DOI: 10.1109/ICALT.2008.84

Kanala, S., T. Nousiainen and M. Kankaanranta, 2013. Using a mobile application to support children's writing motivation. Int. Technol. Smart Educ., 10: 4-14. DOI: $10.1108 / 17415651311326419$

Kazu, İ.Y., 2009. The effect of learning styleson education and teaching process. J. Comput. Sci., 5: 85-94. DOI: $10.3844 /$ jssp.2009.85.94

MacFarlane, S., G. Sim and M. Horton, 2005. Assessing usability and fun in educational software. Proceedings of the Interaction Design and Children, (IDC' 05), ACM, pp: 103-109.

DOI: $10.1145 / 1297277.1297328$

Mazzone, E. and N. Iivari, 2010. Considering context, content, management and engagement in design activities with children. Proceedings of the 9th International Conference on Interaction Design and Children, (IDC' 10), ACM, pp: 108-117.

DOI: $10.1145 / 1810543.1810556$

Mazzone, E., 2007. Requirements gathering in designing technology for children. Proceedings of the 6th International Conference on Interaction Design and Children, (IDC'07), ACM, pp: 197-200.

DOI: $10.1145 / 1297277.1297328$
Moser, C., M. Tscheligi, B. Zaman, V.V. Abeele and L. Geurts et al., 2014. Editorial: Learning from failures in game design for children. Int. J. Child-Comput. Int., 2: 73-75. DOI: 10.1016/j.ijcci.2014.10.001

Politi, E. and N.C.S.R. Demokritos, 2020. Evaluation of mobile apps effectiveness in children with autism social training via digital social stories. Int. J. Int. Mobile Technol., 14: 4-18. DOI: $10.3991 /$ ijim.v14i03.10281

Robins, B., N. Otero, E. Ferrari and K. Dautenhahn, 2007. Eliciting requirements for a robotic toy for children with autism - results from user panels. Proceedings of the International Workshop on Robot and Human Interactive Communication, Aug. 26-29, IEEE Xplore Press, Jeju, South Korea, pp: 101-106. DOI: 10.1109/ROMAN.2007.4415061

Runeson, P., M. Host, A. Rainer and B. Regnell, 2012. Case Study Research in Software Engineering. 1st Edn., John Wiley and Sons, Hoboken, New Jersey.

Sabariah, M.K., P.I. Santosa and R. Ferdiana, 2020. Model of tools for requirements elicitation process for children' s learning applications. Int. J. Adv. Comput. Sci. Applic., 11: 322-328.

DOI: $10.14569 /$ IJACSA.2020.0110340

Skiada, R., E. Soroniati, A. Gardeli and D. Zissis, 2014. EasyLexia: A mobile application for children with learning difficulties. Proc. Comput. Sci., 27: 218-228. DOI: 10.1016/J.PROCS.2014.02.025

Santrock, J.W., 2012. Life-Span Development.

Tang, H.H., C.M. Jheng, M.E. Chien, N.M. Lin and M.Y. Chen, 2013. ICAN: A tablet-based pedagogical system for improving the user experience of children with autism in the learning process. Proceedings of the 1st International Conference on Orange Technologies, Mar. 12-16, IEEE Xplore Press, Tainan, Taiwan, pp: 177-180. DOI: 10.1109/ICOT.2013.6521186

Tran, H.M.T. and F. Anvari, 2016. A five-dimensional requirements elicitation framework for e-learning systems. Int. J. Inform. Electro. Eng., 6: 185-191. DOI: 10.18178/IJIEE.2016.6.3.621

Wiegers, K. and J. Beatty, 2013. Managing software requirements. 